\title{
PENERIMAAN YOUTUBE SEBAGAI SUMBER MAKLUMAT AGAMA ISLAM DALAM KALANGAN MASYARAKAT DI KAMPUNG ULU PUTATAN, SABAH: PENGAPLIKASIAN MODEL PENERIMAAN TEKNOLOGI (TAM) DAN TEORI KREDIBILITI.
}

\author{
THE ACCEPTANCE OF YOUTUBE AS A SOURCE OF ISLAMIC \\ RELIGIOUS INFORMATION AMONG THE COMMUNITY IN KAMPUNG \\ ULU PUTATAN, SABAH: THE APPLICATION OF THE TECHNOLOGY \\ ACEPTANCE MODEL (TAM) AND CREDIBILITY THEORY
}

Intan Kurnia Ahmad ${ }^{1}$

${ }^{1}$ Universiti Malaysia Sabah (UMS)

Dr. Haryati Karim (email: Haryati@ums.edu.y)

\begin{abstract}
In this current era of technology boom, YouTube has become a new alternative for the community to get information about Islam more easily and quickly. YouTube is one of the popular Da'wah medium in the internet, because it is seen as a medium that can attract the interest of the community because of its nature that combines audio and visual elements. In this regard, the community began to use it as a platform for learning and understanding of Islam. However, the scope of open use of YouTube has led to an influx of Islamic religious information. The overflow of such information has indirectly raised the issue of the credibility of the information content received by users. An empirical study of previous studies found that Islamic religious information was accepted due to the fact that YouTube is easy to use and useful. However, from the perspective of the model used is seen as not deep and less focused on the acceptance factor of its content. This is because, it is very important an understanding is built to know how the credibility of Islamic religious information from YouTube is determined. Thus, there is a need to do research to find out the factors of belief in Islamic religious information from YouTube that lead to the acceptance of YouTube as a source of Islamic religious information. Acceptance is something that needs to be studied to anticipate the implications that may exist in life.
\end{abstract}

Keywords: Acceptance, YouTube, Islamic Religious Information, Credibility Theory, Technology Acceptance Model (TAM). 


\begin{abstract}
ABSTRAK
Dalam era ledakan teknologi kini, Youtube telah menjadi alternatif baru bagi masyarakat untuk mendapatkan maklumat agama Islam dengan lebih mudah dan pantas. Youtube merupakan antara medium dakwah popular dalam internet, kerana dilihat sebagai medium yang boleh menarik minat masyarakat kerana sifatnya yang menggabungkan elemen audio dan visual. Sehubungan dengan itu, masyarakat mula memanfaatkannya sebagai platform untuk pembelajaran dan pemahaman mengenai agama Islam. Namun, ruang lingkup penggunaan Youtube yang terbuka menyebabkan berlakunya kebanjiran maklumat agama Islam. Limpahan maklumat tersebut secara tidak langsung telah menimbulkan isu kredibiliti kandungan maklumat yang diterima oleh pengguna. Kajian empirikal terhadap kajian lepas mendapati maklumat agama Islam diterima atas faktor Youtube mudah diguna dan berguna. Namun, dari perspektif model yang digunakan dilihat tidak mendalam dan kurang memfokuskan terhadap faktor penerimaan terhadap kandungannya. Ini kerana, adalah amat penting satu pemahaman dibina untuk mengetahui bagaimana kredbiliti maklumat agama Islam dari Youtube ditentukan. Justeru, wujudnya keperluan untuk membuat penelitian bagi mengetahui faktor kepercayaan terhadap maklumat agama Islam dari Youtube yang mendorong kepada penerimaan Youtube sebagai sumber maklumat agama Islam. Penerimaan adalah sesuatu yang perlu dikaji untuk menjangkakan implikasi yang mungkin wujud dalam kehidupan.
\end{abstract}

Kata Kunci: Penerimaan, Youtube, Maklumat Agama Islam, Teori Kredbiliti, Model Penerimaan Teknologi (TAM).

\title{
Pengenalan
}

Mutakhir ini, bidang komunikasi di Malaysia sedang mengalami perkembangan yang pesat hasil daripada ledakan teknologi maklumat dan komunikasi (ICT) yang berlaku. Perkembangannya dilihat sangat ketara khususnya dalam aktiviti perolehan maklumat (Ahmad Zaini, 2014), ekoran daripada kemunculaan jaringan internet yang disusuli dengan penciptaan teknologi komunikasi Web 2.0 seperti media sosial. Umumnya, penggunaan jaringan internet secara meluas berlaku sekitar abad ke-21, iaitu pada Era Media Komunikasi Interaktif. Era ini seperti mana yang telah digariskan oleh Everett M. Rogers (1986), dalam Suharto (2017), yang mana berlaku empat era peralihan media komunikasi, iaitu era media tulis, era media cetak, era telekomunikasi, dan era media komunikasi interaktif. 
Rentetan daripada peralihan yang berlaku, secara tidak langsung memperlihatkan arus aktiviti perkongsian dan penerimaan maklumat berubah agak drastik dan ketara. Masyarakat dilihat menunjukkan kebergantungan yang tinggi dalam penggunaan media sosial. Penggunaannya telah menjadi satu alternatif baru, yang mana lebih gemar menggunakan media berasaskan internet berbanding televisyen dan akhbar (Dimmick, Chen dan Li, 2004; Schafer, 2010; Nur Amalina Mohd Zain, Ezhar Tamam \& Rosya Izyanie Shamshudeen, 2015). Hal ini demikian kerana, media sosial mampu memberi ruang kepada masyarakat untuk berkongsi dan mendapatkan maklumat dengan lebih mudah (Mohd Azul Mohamad Salleh \& Nurul Madiha Mohd Ilham, 2017). Sifatnya yang interaktif dan menekankan konsep komunikasi secara dua hala, (Andreas Kaplan \& Michael Haenlein, 2010), menjadikan sudah tidak ada persoalan mengenai limitasi bermaklumat (Jamiah Manap, Mohd Rezal Hamzah \& Aizan Sofia Amin et al, 2016; Mohd Azul Mohamad Salleh et al, 2017).

Kecenderungan terhadap penggunaan media sosial tersebut menjadikan Malaysia sebagai negara ke-9 paling aktif media sosial sepanjang tahun 2018, iaitu sebanyak 79\%. Daripada jumlah tersebut, pengguna memperuntukkan purata tiga jam sehari. Kenyataan yang dikeluarkan oleh artikel Astro Awani bertarikh 30 Januari 2019 itu turut menyatakan bahawa peratusan tersebut menunjukkan peningkatan sebanyak sembilan peratus berbanding tahun sebelumnya. Antara media sosial yang menyumbang kepada peningkatan kadar peratusan tersebut termasuklah laman sosial Youtube. Berdasarkan kepada laporan tahunan Suruhanjaya Komunikasi dan Multimedia Malaysia (2018), mendapati peratusan pengguna Youtube terus meningkat setiap tahun. Sehingga tahun 2018, pengguna Youtube mencatat peratusan $48.3 \%$ berbanding tahun sebelumnya dengan perbezaan tiga peratus.

Berdasarkan kepada peningkatan tersebut mendapati bahawa antara faktor penyumbang masyarakat melayari Youtube adalah disebabkan oleh aktiviti perkongsian dan pencarian pencarian maklumat. Aktiviti pencarian maklumat merupakan perkara asas yang diperlukan sebagai sumber untuk memenuhi keperluan maklumat (Ramnah \& Lili, 2011). Pencarian maklumat penting sebagai satu proses pembelajaran (Siti Zanariah Haji Yusoff, Nor Azura Adzharuddin \& Jusang Bolong, 2014), yang mana melibatkan proses mencari, mendapatkan dan menggunakan maklumat tersebut bagi tujuan tertentu (Vakkari, 1999).

Kempen kesedaran Teknologi Maklumat dan Komunikasi (TMK) yang dilancarkan oleh mantan Perdana Menteri, Dato' Seri Dr. Mahathir Mohamed, pada 11 Oktober 1997 (Fadzli Adam, Ab Hamid Ali, Marhana Mohamed Anuar \& Engku Muhammad Tajuddin Engku Ali (2015), dilihat telah memainkan 
peranan yang besar dalam usaha merancakan lagi pengguaan media atas talian seperti Youtube. Ianya dianggap sebagai kuasa besar kerana kekuatannya dalam aktiviti perkongsian dan penerimaan maklumat merentasi sempadan masa dan tempat dengan mudah dan pantas. Pelbagai perkongsian maklumat dari pelbagai bidang seperti ekonomi, politik pendidikan sosial dan keagamaan boleh dilakukan selama 24 jam tanpa batasan.

Walaubagaimanapun, di Malaysia, media sosial seperti Youtube sebagai bahan rujukan dan pembelajaran agama oleh masyarakat dilihat telah mula menjadi isu yang hangat dibincangkan umum ketika ini. Hal ini kerana, dalam proses mendapatkan ilmu berkaitan agama Islam, secara tradisinya individu perlu menghadiri majlis pengajian samada secara formal ataupun tidak formal. Pengajian tidak formal yang bersifat tradisional biasanya dijalankan di masjid, surau dan pelbagai ceramah umum yang dianjurkan. Manakala pengajian formal pula seperti pengajian di sekolah pondok, sekolah agama, kolej atau universiti yang mempunyai silibus yang lebih tersusun (Umar Halim \& Samsudin A. Rahim. 2010. Penglibatan Digital: Akses dan Penggunaan E-Agama dalam Kalangan Generasi Muda Muslim. Jurnal Komunikasi Jilid 27 (2): 121 - 135. UKM. Namun, kewujudan Youtube kini dilihat membawa perubahan besar dalam aspek proses mendapatkan ilmu agama Islam, yang mana maklumat boleh diperolehi hanya menggunakan hujung jari sahaja. Dalam situasi ini, individu itu sendiri yang memainkan peranan utama terhadap setiap maklumat yang mereka diperolehi.

Al-Qur'an mengingatkan "Jangan kamu berpijak kepada seuatu yang kamu tiada ilmu tentangnya"(al-Isra' 17:36). Sekiranya terdapat persoalan yang tidak difahami, sebaiknya perlu merujuk kepada meraka yang pakar. "Tanyalah kepada mereka yang ahli sekiranya kamu tidak mengetahui,(al-Nahl 16:43)".

\section{YouTube}

Youtube adalah laman sosial yang tergolong dalam kelompok bentuk aplikasi content communities (Kaplan, A. M., \& Haenlein, M., 2010). Ianya membenarkan pengguna untuk mendapatkan maklumat seperti video, gambar, ebook, dan audio. Maklumat yang diperolehi dari Youtube tidak hanya terhad kepada sesuatu bidang tertentu sahaja, malah mencakupi pelbagai bidang terutamanya hiburan, ekonomi dan politik (Fadzli Adam, Ab Hamid Ali \& Marhana Mohamed Anuar et al, 2015; Zul Hilmi Abdullah, Halimaton Sa'adiah Ariffin \& Shaharudin Ismail et al, 2016). Namun, seiring dengan kemajuan yang dikecapi, memperlihatkan Youtube telah banyak digunakan sebagai salah satu 
medium keagmaan (Yuni Fitriani, 2017), termasuklah agama Islam (Siti Rokiah Ab Rahman \& Fadzli Adam, 2015).

\section{Latar belakang kajian}

Pergantungan masyarakat terhadap Youtube untuk mendapatkan maklumat berkaitan agama Islam dilihat semakin meningkat. Walaupun media konvensional masih digunakan sebagai sumber maklumat (Nur Amalina Mohd Zain, Ezhar Tamam \& Rosya Izyanie Shamshudeen, 2015), namun masyarakat kini yang terlalu terdedah kepada persekitaran berasaskan internet menyebabkan mereka sentiasa inginkan sesuatu maklumat dengan pantas (Mohd Sobhi Ishak, 2014). Justeru, kecenderungan masyarakat terhadap aplikasi Youtube dalam bermaklumat memaksa para pendakwah Islam untuk turut memanfaatkannya bagi mengelak dari keterbelakangkan oleh era pemodenan yang dikecapi. Penyampaian maklumat agama Islam perlu dilakukan dengan mengaplikasikan segala bentuk atau kaedah yang dinamik (Azizan Had, 2014) sesuai dengan minat dan kecenderungan masyarakat. Dalam kajian yang dijalankan oleh Rosmawati (2011); Nadia Fauzi (2017), penggunaan laman web sosial seperti Youtube berperanan besar dalam menembusi benteng sasaran dakwah remaja yang gemarkan gajet teknologi pelengkap interaksi sosial, sekaligus menjadi faktor kepada pengimplementasian dakwah alaf baru. Pengguna yang menggunakan Youtube sebagai sumber maklumat Islam kini semakin dihimpit dengan lambakan maklumat Islam yang tidak ditapis, dan boleh menjerumus ke kancah kekeliruan fakta. Keadaan ini dikhuatiri akan menyebabkan pengguna mempercayai maklumat yang tidak tepat, sekaligus memberikan kesan besar dalam mempengaruhi pemikiran dan sikap. Dalam hal ini, tahap pendidikan agama yang baik dilihat merupakan kunci dalam sesuatu keputusan yang diambil. Hal ini demikian kerana, individu yang mempunyai latar belakang pendidikan yang baik sudah tentu mereka boleh membuat perbandingan menggunakan pengetahuan yang dimiliki (Noor Azaian binti Abdul Talib, Mohd Yusof Abdullah \& Mohd Azul mohamad Salleh, 2017; Fadzil Adam, Ab Hamid Ali \& Marhana Mohamed Anuar et al., 2015). Ini dibuktikan dengan kajian yang dijalankan oleh Siti Rokiah Ab Rahman \& Fadzli Adam (2016), yang mana menunjukkan bahawa responden yang mempunyai latar belakang pendidikan yang baik menerima Youtube sebagai sumber maklumat agama Islam disebabkan dua faktor, iaitu persepsi kemudahgunaan dan persepsi kebergunaan. Walaubagaimanapun, tidak mempercayai sepenuhnya maklumat yang terdapat dalam Youtube, sebaliknya melakukan verifikasi terhadap sumber dan kandungan maklumat terlebih dahulu. Namun berbeza dengan individu yang mempunyai latar belakang pendidikan minimum, yang mana mereka mungkin menghadapi 
kesukaran dalam menentukan kesahihan sesuatu maklumat (Zulkiple, 2002). Dikhuatiri mereka hanya menerima maklumat tanpa ragu - ragu untuk mempersoalkan kebolehpercayaan sumber dan mesej yang diterima (Alivi, Ghazali, Tamam \& Osman, 2018; Wilson, Leong, Nge \& Hong, 2011). Dalam Surah al-Nahl, ayat 43, Allah S.W.T berfirman yang bermaksud; "Dan tidaklah kami mengutuskan rasul-rasul sebelummu (Wahai Muhammad) melainkan daripada kalangan orang-orang lelaki, yang kami wahyukan kepada mereka. Oleh itu, bertanyalah kamu (wahai golongan musyrik) kepada orang orang yang berpengetahuan agama jika kamu tidak mengetahui". Justeru, pengkaji merasakan masih terdapat beberapa perkara yang tidak dikupas secara khusus dan mendalam. Aspek yang kurang diperjelaskan dalam kajian berkaitan penerimaan dan kepercayaan terdahulu ialah dari sudut pengguna yang memiliki tahap pendidikan minimum. Tambahan lagi, teori yang digunakan untuk melihat faktor kepercayaan pengguna terhadap kredibiliti dan kebolehpercayaan terhadap maklumat agama Islam dari Youtube dirasakan masih perlu diberi perhatian agar mampu mencapai objektif yang ditetapkan. Maka pengkaji merasa tertarik untuk melakukan penelitian bagi mengetahui faktor kepercayaan masyarakat yang mempunyai tahap pendidikan minimum terhadap maklumat agama Islam dari Youtube yang mendorong kepada penerimaan Youtube sebagai sumber maklumat agama Islam, dengan menggabungkan model Penerimaan Teknologi (Davis, 1986) dan teori Kredibilti Sumber (Hovland, 1953). Penerimaan adalah sesuatu yang perlu dikaji untuk menjangkakan implikasi yang mungkin wujud dalam kehidupan. Kajian ini berfokus kepada dua (2) objektif iaitu (1) mengkaji hubungan antara tahap pendidikan agama responden dengan faktor kepercayaan terhadap maklumat agama Islam dari Youtube; dan (2) menganalisis tahap kepercayaan responden terhadap maklumat agama Islam dari Youtube.

Penyelidikan ini kelak dapat memberi impak kepada masyarakat dalam pelbagai peringkat. Ianya dilihat mampu memberikan kesedaran kepada masyarakat khususnya para pendakwah Islam bahawa dengan adanya platform seperti Youtube, maka adalah sangat mudah untuk menyampaikan dakwah kepada masayarakt pada masa kini. Ini sepertimana yang dituntut oleh Allah S.W.T, yang mana setiap umat Islam diletakkan diperingkat wajib menyampaikan mesej dakwah mengikut kadar kemampuan masing - masing. Zulkiple (2001), Allah S.W.T berfirman dalam surah Al-Imran, ayat 104 yang bermaksud: "dan hendaklah ada di antara kamu segolongan umat yang menyeru kepada kebajikan, menyuruh kepada yang ma'ruf dan mencegah dari yang munkar; merekalah orang-orang yang beruntung". Dari 'Abdullah bin 'Umar ra dituturkan, bahwasanya Rasulullah S.A.W bersabda, "sampaikanlah dariku walaupun satu ayat" (HR. Bukhari). Islam menggalakkan pengikutnya menggunakan setiap saluran yang boleh menyampaikan dakwah kepada sasaran dengan syarat ianya 
tidak bercanggah dengan Islam dan selagi mana tidak melepasi sempadan syarak. Masyarakat perlu berani mengaplikasi apa juga jenis teknologi komunikasi yang ada bagi memperkukuh metodologi dakwah yang sedia ada (Ruzain, 2011).

Manakala kepentingan penyelidikan ini kepada penerima maklumat, yakni pencari maklumat agama Islam melalui Youtube pula diharapkan akan mampu menyedarkan mereka bahawa adalah sangat penting dalam memegang teguh dan mengamalkan prinsip Tabayyun sebelum menerima apa juga jenis maklumat. Hal ini secara tidak langsung mampu mendidik mereka untuk membuat penilaian terlebih dahulu sebelum menerima dan mempercayai maklumat agama Islam dari Youtube. Seperti yang dijelaskan di dalam al - Quran surah al - Hujurat, ayat 6, Allah berfirman yang bermaksud "Hai orang - orang yang beriman, jika datang kepadamu orang fasik membawa suatu berita, maka periksalah dengan teliti, agar kamu tidak menimpakan suatu musibah kepada suatu kaum tanpa mengetahui keadaannya yang menyebabkan kamu menyesal atas perbuatanmu itu" (al - Hujurat, 49:6). Masyarakat perlu mengamalkan etika dan adab dalam menerima maklumat. Dengan demikian pengguna dapat mengelakkan diri daripada menerima maklumat yang tidak tepat.

\section{Sorotan Literatur}

\section{Pandangan Islam mengenai Youtube sumber maklumat agama Islam}

Jika dilihat dalam konteks perkembangan aktiviti perkongsian dan penerimaan sebarang bentuk maklumat berkaitan agama Islam dari dahulu sehingga kini, jelas bahawa Islam tidak menetapkan penggunaan terhadap satu - satu kaedah tertentu dan tidak pula mengehadkan kepada satu - satu media sahaja. Tidak ada larangan dalam menggunakan Youtube sebagai sumber maklumat agama, malah Islam lebih menggalakkan masyarakat memanfaatkan teknologi yang ada selagi tidak bercanggah dengan al-Quran dan hadis (Ruzain, 2011; Ahmad Zaini, 2014), bagi memantapkan lagi pegangan dan kepercayaan terhadap agama (Mohd Sobhi Ishak, Norizah Aripin dan Mohd Nizho Abdul Rahman, 2016). Sehubungan dengan itu, dalam era teknologi moden kini, para pendakwah khususnya, haruslah bijak dalam memilih dan mengaplikasikan kaedah yang sesuai terutama yang menjadi minat masyarakat semasa serta mengikut kesesuaian zaman.

\section{Kajian Empirikal}

Kajian empirikal terhadap beberapa kajian lepas menunjukkan bahawa laman sosial Youtube terkenal sebagai laman untuk mendapatkan hiburan. Ini 
dibuktikan melalui kajian yang dijalankan oleh Fatty Faiqah, Muh. Nadjib \& Andi Subhan Amir (2016), mengenai Youtube Sebagai Sarana Komunikasi Bagi Komunitas MAkassarvidgram: Pemanfataan Youtube. Kajian tersebut mendapati responden lebih memanfaatkan Youtube sebagai sarana untuk mendapatkan infromasi terkini dan bersifat hiburan. Responden lazimnya menggunakan Youtube untuk mencari sesuatu yang sedang viral di dunia maya atau memantau artis-artis yang menjadi kegemaran mereka. Dapatan yang diperolehi oleh Aritas Puica Sianipar (2010), berkenaan Pemanfaatan Youtube di Kalangan Mahasiswa (Studi Penggunaan Youtube di Kalangan Mahasiswa Ilmu Komunikasi FISIP USE Medan dengan Pendekatan Uses and Gratification), turut menunjukkan bahawa hiburan merupakan salah satu faktor utama mereka menggunakan Youtube. Hal ini dimana, responden melayari Youtube dan mengakses lagu - lagu atau video tarian, sebagai cara untuk menghiburkan diri daripada permasalahan hidup yang dihadapi.

Walaubagaimanapun, seiring peredaran zaman yang berlaku, penggunaannya dilihat bukan lagi hanya berbentuk hiburan semata - mata, tetapi boleh menjadi salah satu medium berbentuk ilmiah yang digunakan untuk tujuan menyampaikan dan berkongsi maklumat (Tan \& Carol, 2013). Ini dapat dilihat melalui penyelidikan yang dijalankan pada tahun 2013, oleh Mohd Sazili Shahibi, Nurhayati Hussin, Hamka Mohd noor \& Muhammad Saufi Mohd Hanafiah, mengenai Persepsi Terhadap Kredibilti Maklumat Politik di Internet dalam Kalangan Generasi Muda. Kajian mendapati bahawa sejak tahun 2008 lagi media atas talian seperti Youtube telah mula digunakan secara pesat sebagai saluran maklumat untuk menyampaikan maklumat kepada pengundi parti politik. Ianya digunakan bertujuan memberi kemudahan dalam menghantar maklumat tanpa sebarang batasan samada masa atau tempat, berbanding sebelum ini yang mana masyarakat hanya mendapatkan maklumat politik melalui media cetak seperti surat khabar, buku dan media elektronik terutama radio dan televisyen.

Youtube sememangnya dilihat memiliki manfaat yang sangat penting sebagai sarana penyebaran pelbagai bentuk informasi. Sejajar dengan itu, secara perlahan memperlihatkan bidang keagamaan juga turut mula mengambil langkah proaktif dengan memanfaatkan kelebihan yang ada pada Youtube untuk menyampaikan maklumat berkaitan agama Islam. Walau bagaimanapun, dalam konteks kajian di Malaysia, masih belum banyak tinjauan dilakukan terhadap maklumat Islam dari atas talian termasuklah Youtube sama ada dari persepktif pengguna dan sebagainya (Umar Halim \& Samsudin A. Rahim, 2010). Justeru, pengkaji merasakan wujudnya keperluan untuk membuat penyelidikan berkenaan Youtube dan maklumat agama Islam. 


\section{Metod Kajian}

Kajian ini menggunakan kaedah berbentuk kuantitatif dengan menggunakan instrumen set borang soal selidik. Soal selidik yang digunakan dalam kajian ini berasaskan kepada instrumen yang digunakan oleh Budi Anto Mohd. Tamring (2008), iaitu dengan menggunakan Belief Silence Scale (Jackson, 1981) bagi mengukur tahap keagamaan responden. Namun dalam kajian ini, pengubahsuaian soal selidik dilakukan agar menepati keperluan kajian. Walaubagaimanapun, pengubahsuaian soal selidik akan melalui beberapa prosedur untuk mengekalkan kesahannya, iaitu dengan melakukan kajian rintis terlebih dahulu sebelum kajian sebenar dijalankan. Kajian menggunakan teknik persampelan rawak mudah dengan mengambil kira pandangan yang dikemukakan oleh Krejcie \& Morgan (1970) berkenaan bilangan sampel. Kesemua keputusan jawapan yang diperolehi daripada responden melalui borang soal selidik yang diedarkan kemudiannya akan dianalisis dengan menggunakan perisian Statistical Package Social Science (SPSS).

\section{Dapatan Kajian dan Perbincangan}

\section{Penggunaan Youtube Bagi Tujuan Pembelajaran Agama Islam}

Hal ini demikian kerana, sejak akhir-akhir ini penggunaan Youtube dalam proses pembelajaran agama Islam semakin meningkat. Kajian mendapati responden yang mempunyai pengetahuan agama yang baik sememangnya bergantung kepada Youtube untuk mendapatkan dan mempelajari agama Islam (Siti Rokiah Ab. Rahman et. al., (2015). Ini sejajar dengan hasil dapatan kajian yang dijalankan oleh Ab. Hamid Ali et. al., (2014); Norizah Aripin et. al., (2016), yang mana mendapati bahawa golongan yang mempunyai latar belakang pendidikan baik menerima Youtube sebagai sumber maklumat agama Islam. Dapatan tersebut dikuatkan lagi dengan kajian yang dijalankan oleh Mohd Faisal Mustaffa, Norizah Aripin \& Mohd Sobhi Ishak (2019), ke atas pelajar Universiti Utara Malaysia, yang mana menunjukkan bahawa pelajar memanfaatkan Youtube untuk mencari maklumat agama khususnya berkaitan Syariah. Tiga carian paling tinggi dalam kalangan generasi muda Islam, iaitu mengenai persoalan aurat, solat dan perhubungan antara lelaki dan perempuan.

Beberapa kajian lepas yang diperoleh kebanyakannya hanya memfokuskan kepada pelajar Institusi Pengajian Tinggi dan mereka yang mempunyai latar belakang pendidikan yang baik. Sehubungan dengan itu, pengkaji berpendapat bahawa perlu untuk menjalankan satu kajian yang terbuka 
dalam kalangan masyarakat awam, dan memberi fokus kepada golongan yang mempunyai pendidikan yang minimum. Ini setelah mengambil kira cadangan oleh beberpa pengkaji lepas termasuklah Ab. Hamid Ali et. al., (2014) dan Siti Rokiah Ab Rahman et al., (2015), yang mana masing - masing berpendapat bahawa kajian diperluaskan ke atas masyarakat awam.

\section{Kepercayaan Terhadap Maklumat Agama Islam Dari Youtube}

Penerimaan ke atas masyarakat awam dan terhadap golongan yang mempunyai pendidikan yang minimum adalah sesuatu yang yang perlu dikaji dengan lebih mendalam bagi mengetahui bagaimanakah bentuk kepercayaan mereka terhadap kandungan maklumat agama Islam dari Youtube yang diperolehi. Ini sekaligus dapat mencapai hasil penemuan baru yang lebih memberangsangkan. Ini adalah kerana, jika dilihat dari sudut penerimaan golongan yang mempunyai latar belakang pendidikan yang baik, walaupun mereka bersedia menerima Youtube sebagai sumber maklumat agama Islam, namun mereka tidak mempercayai sepenuhnya maklumat yang terdapat dalam Youtube, sebaliknya melakukan verifikasi terhadap sumber dan kandungan maklumat terlebih dahulu (Siti Rokiah Ab Rahman et., al., 2015; Abd Hadi bin Borhan \& Zulkiple bin Abd Ghani, 2015). Ini kerana, ruang bebas Youtube boleh dimanipulasi atas tujuan memesongkan dan merosakkan kefahaman Islam seseorang. Perkara ini dikhuatiri membawa pemasalahan kepada pengguna yang mempunyai pendidikan yang minimum, yang mana kemungkinan besar akan menerima maklumat agama Islam dari Youtube tanpa mempersoalkan kebolehpercayaannya. Maka, pengkaji merasakan bahawa perlunya satu kajian dibuat terhadap kelompok berpendidikan minimum untuk melihat bagaimana kepercayaan mereka terhadap maklumat agama dari Youtube.

\section{Pemilihan Teori dan Model Penyelidikan}

Tambahan lagi, kajian lepas mendapati maklumat agama Islam dari media sosial termasuk Youtube kebanyakannya diterima atas persepsi sifat Youtube yang mudah diguna dan kerana Youtube berguna (Ika destina, Ali Salman \& Mohd. Helmi Abd. Rahim, 2013; Mohd Sobhi Ishak, 2014; Faradillah Iqmar Omar, Nurzakira Afnee \& Hazlin Falina, 2015; Zul Hilmi Abdullah, Halimaton Sa'adiah \& Ariffin, 2016). Dua persepsi tersebut adalah berpandukan kepada model Penerimaan Teknologi (TAM), oleh Davis (1989). Walaubagaimanapun, pengkaji berpendapat bahawa dari perspektif model yang digunakan dilihat tidak mendalam dan kurang memfokuskan terhadap penerimaan terhadap 
kandungannya. Ini kerana, adalah amat penting satu pemahaman dibina untuk mengetahui bagaimana kredbiliti maklumat agama Islam dari Youtube ditentukan terutama oleh golongan yang mempunyai pendidikan yang minimum. Justeru, dalam penyelidikan akan dijalankan berpandukan kepada gabungan model Penerimaan Teknologi (Davis, 1989) dan Teori Kredibiliti Sumber (Hovland, 1953). Wujudnya keperluan untuk membuat penelitian bagi mengetahui bagaimana kepercayaan terhadap maklumat agama Islam dari Youtube yang mendorong kepada penerimaan Youtube sebagai sumber maklumat agama Islam bagi menjangkakan implikasi yang mungkin wujud dalam kehidupan.

\section{Kesimpulan}

Youtube telah memberi kemudahan bagi mempelajari, memahami dan mengenali Islam dengan mudah. Ini menunjukkan bahawa Youtube merupakan medium yang penting bagi masyarakat muslim hari ini dalam konteks mendapatkan ilmu dan memahami tentang Islam. Namun ianya harus digunakan secara bijak dalam menentukan kesahihan maklumat yang tepat kerana terdapat aspek - aspek yang boleh memberikan kesan negatif dalam kehidupan yang akhirnya boleh membawa kepada pemahaman dan tanggapan yang salah terhadap Islam.

\section{Rujukan}

\section{Artikel Jurnal}

Abd Hadi bin Borhan \& Zulkiple bin Abd Ghani. (2015). Pola Pendedahan Internet dan Impaknya Terhadap Kefahaman Islam di Kalangan Ahli Akademik di UKM dan USIM. Jurnal Komunikasi - Malaysian Journal of Communication. Jilid 31(2); 405 - 421.

Adam, F., Anuar, M. dan Ali, A.H. (2014) the use of blog as a medium of Islamic da'wah in Malaysia. International Journal of Sustainable Human Development, 2(2):74-80.

Ahmad Zaini (2014). Media Teknologi Informasi Modern Sebagai Wasilah Dakwah. At - Tabsyir: Jurnal Komunikasi Penyiaran Islam.Volume 2(1) $-57-72$.

Kaplan, A. M., \& Haenlein, M. (2010). Users of The World, Unite! The Challenges and Opportunities of Social Media. Business Horizons. Volume 53(1), 59 - 58. 
Dimmick, J., Chen, Y., \& Li, Z. (2004). Competition between the internet and traditional news media: The gratification-opportunities niche dimension. The Journal of Media Economics, 17(1), 19-33

Fadzli Adam \& Ab Hamid Ali, Marhana Mohamed Anuar \& Engku Muhammad Tajuddin Engku Ali. (2015). Cabaran Media Baru Sebagai Medium pembelajaran Agama dan Penyelesaiannya dari Persepektif Islam. Jurnal Islam dan Masyarakat Kontemporari. Volume 9(9), 101 - 139.

Fatty Faiqah, Muh. Nadjib \& Andi Subhan Amir. (2016). Youtube Sebagai Sarana Komunikasi bagi Komunitas Makassarvidgram. Jurnal Komunikasi KAREBA. Vol. 5(2); 259 - 272.

Hanudin, A. (2008). E-Business from Islamic Perspectives: Prospects and Challenges. Journal of Internet Banking and Commerce, 13(3).

Hanudin. (2008). An Analysis of Islamic Ethic in Islam and Medium Enterprise (SMEs). Unitare E - Journal 4(1):46-58.

Ika Destiana, Ali Salman \& Mohd. Helmi Abd. Rahim. (2013). Penerimaan Media Sosial: Kajian dalam kalangan pelajar universiti di Palembang. Jurnal Komunikasi. Jilid 29(2):125-140.

Noor Azaian binti Abdul Talib, Mohd Yufof Abdullah \& Mohd Azul Mohammad Salleh. (2017). Cabaran Dakwah di Alam Siber. e - Bangi, Journal of Social Science and Huminities. Volume 14(7).

Nur Amalina Mohd Zain, Ezhar Tamam \& Rosya Izyanie Shamshudeen. (2015). Media Baharu: Medium Pilihan Pelajar Islam bagi Mengetahui Isu Halal dan Haram Urusan Muamalat. Global Media Journal - Malysian Edition. Volume 5(2), 49 - 67.

Siti Eizaleila Mustafa \& Azizah Hamzah. (2010). Media Sosial: Tinjauan Terhadap Laman Jaringan Sosial Dalam Talian Tempatan. Jurnal Pengajian Media Malaysia. Vol. 12, No. 2, Pages 37-52.

Umar Halim \& Samsudin A. Rahim (2010). Penglibatan Digital: Akses dan Penggunaan E-Agama Dalam Kalangan Generasi Muda Muslim. Jurnal komunikasi Jilid 27(2): 121-135. UKM.

Zulkiple Abd Ghani. (2001). Komunikasi Islam Sebagai Komunikasi Alternatif. Jurnal Islamiyyat, 2(22): 79- 89.

Yuni Fitriani. (2017). Analisis Pemanfataan Berbagai Media Sosial Sebagai Sarana Penyebaran Informasi bagi Masyarakat. Paradigma - Jurnal Komputer dan Informatika. Volume 19(2), 148 - 152.

Buku

$\mathrm{Al}-$ Quran

Krejcie, R. V., \& Morgan, D. W. (1970). Determining Sample Size for Research Activities, Educational and Psychological Measurement. 30, 607-610. 
Little John. (1978). Power and The State. British sociological Association. John's Road, London.

Noor Shakirah Mat Akhir. (2006). Dakwah dan Cabaran Teknologi Maklumat. Universiti Sains Malaysia; Pulau Pinang.

Rosmawati, H.P., (2011). Mengenal Ilmu Komunikasi, Bandung: PT. Remaja. Rosdakarya. Indonesia.

Ruzain Syukor Mansor. 2011. Dakwah dan Teknologi Maklumat. Putrajaya: Penerbit JAKIM.

Zakariya, N., \& Mohamad, A. B. U. D. (n.d.). Media Sebagai Wasilah Dakwah.

Tesis

Aritas Puica Sianipar. (2010). Pemanfaatan youtube di kalangan mahasiswa. (Studi Penggunaan Youtube di Kalangan Mahasiswa Ilmu Komunikasi FISIP USU Medan dengan Pendekatan Uses and Gratification). 1 10.

Kalangan, D., Di, G. Y., Penyelidikan, I., \& Islam, K. (2015). Penggunaan Youtube Sebagai Medium Pembelajaran Agama, 2015(June), 853-861.

Misbakhul Khoiri. (2014). Dakwah Melalui Jejaring Sosial Facebook K.H Abdullah Gymnasiar (Studi Teori Efektivitas Oleh Stewart. L Tubbs Dan Silvia Moss). Universitas Islam Negeri Sunan Kalijaga Yogyakarta.

Mohd Sobhi Ishak. (2014). Pemodelan Penerimagunaan Maklumat Berkaitan Islam Di Internet: Pengaplikasian Model Penerimaan Teknologi, 6(2), $49-61$.

Mohd Shobi Ishak, Musa Abu Hassan, Siti Zobidah Omar dan Jusang Bolong. (2011). Kredibiliti Maklumat Sebagai Faktor Anteseden yang Mempengaruhi Tanggapan Pengguna dalam Model Penerimaan Maklumat Berkaitan Islam di Internet. Bangi: UKM.

Mohd Sazili Shahibi, Hasnah Hashim, Juwahir Ali \& Muhamad Khairul Nizam Zaini. (2011). Kredibiliti Maklumat Digital dari Internet. Informika, Jilid1, 2011:37-4

Norizah Aripin Awan Ismail, Mohd Sobhi Ishak, Nik Adzrieman Abdul Rahman, Mohd Nizho Abdul Rahman Mot Madon \& Mohd Faisal Mustaffa. (2016). "Youtube" Dan Generasi Muda Islam: Satu Pendekatan Kelompok Fokus Dalam Kalangan Pelajar Universiti. 1- 27.

Siti Rokiah Ab Rahman \& Fadzli Adam. (2015). Kredibiliti Youtube Sebagai Medium pembelajaran Agama dalam Peradaban Islam Kontemporari.593 -599 . 
Suharto (2017). Media Sosial Sebagai Medium Komunikasi Dakwah. Institusi Agama Islam Negeri Palu. Volume13 (2).

Yu, J., Ha, I., Choi, M., \& Rho, J. (2005). Extending the TAM for a t-commerce. Information \& Management, 42, 965-976.

Zul Hilmi Abdullah, Halimaton Sa'adiah Ariffin, Shaharudin Ismail \& Ahmad Nzarul Rosli. (2016). Kebolehpercayaan maklumat Elektronik: Tinjauan Awal Terhadap Pelajar Tamhidi.

Sumber internet

Nadia Fauzi. (2017). Penggunaan Media Sosial dalam Dunia Tanpa Sempadan: Suatu Kebaikan atau Keburukan. Institut Latihan Kehakiman dan Perundangan:http://www.ilkap.gov.my/download/kertaspenyelidikan/PM SDDTS18122017.pdf

Astro Awani (30 Januari 2019): http://www.astroawani.com/gayahidup/malaysia-negara-ke-9-paling-aktif-media-sosial-ke-5-paling-ramaiguna-e-dagang-laporan-166998

\section{Conference Proceeding}

Ab. Hamid Ali, Fadzli Adam, Wan Solihin Wong Abdullah \& Wan Abd. Aziz Wan Mohd Amin. (2014). Penerimaan blog sebagai medium agama dalam kalangan pelajar IPTA di Malaysia. Proceeding of the International Conference on Arabic Studies and Islamic Civilization. ICasic 2014. 4-5 Mac 2014, Kuala Lumpur, Malaysia.

Azizan Had. (2014). Dakwah Melalui Internet di Malaysia: Masalah dan Cabaran. Seminar Antarabangsa Dakwah \& Etnik 2014; Dakwah \& Etnik: Perspektif Multi-disiplin Disunting oleh: Anuar Puteh \& Ahmad Irdha Mokhtar. Pusat Kajian Dakwah Orang Asli dan Pribumi, UKM, Bangi, Selangor.

Faradillah Iqmar Omar, Nurzakira Afnee \& Hazlin Falina. (2015). Hubungan Penggunaan Media Sosial dan Penerimaan Mesej Dakwah. Proceeding of the 2nd International Conference on Management and Muamalah. $181-191$.

Jamiah Manap, Mohd Rezal Hamzah, Aizan Sofia Amin, Nurul Nabila Mohd Izani,Fazilah Idris, Salasiah Hanin Hamjah, Noordeyana Tambi, Arena Che Kasim, Norul, Huda Sarnon, Salina Nen, Nor Jana Saim. (2016). Penggunaan dan Implikasi Media Sosial Terhadap remaja Generasi Z. International Conference on Social \& Economic Development (Icesed), $1-3$. 
Siti Rokiah Ab Rahman dan Fadzli Adam. 2015. Penggunaan Youtube sebagai Medium Pembelajaran agama dalam kalangan Generasi $Y$ di Terengganu, Malaysia. E- Proceeding of the International Conference on Social Science Research, ICSSR 2015 (e-ISBN 978-967-0792-040). 8 \& 9 June 2015, Meliá Hotel Kuala Lumpur, Malaysia. 